\title{
Micro-hardness and residual stress relaxation of 2024 T351 aluminum alloy
}

\begin{abstract}
The residual stress relaxation can be divided into two stages: The first cycle relaxation and the following cycles. In both stages, residual stress relaxed considerably from the initial state. The aim of this study is to investigate the residual stress relaxation and microhardness reduction after first and second cyclic load. A 2024 T351 aluminum alloy specimens were shot peened into three shot peening intensities. The fatigue test for first and second cyclic loads of two loads $15.5 \mathrm{kN}$ and $30 \mathrm{kN}$ was performed. The initial residual stress and residual stress after the first and second cycle stress was measured for the three shot peening intensities using X-ray diffraction. Microhardness test was performed for each specimen. The results showed that the residual stress relaxation for first cycle was reached more than $40 \%$ of the initial residual stress and it depends on the load amplitude, and microhardness decreased for the first cycle reached $22 \%$ and also it depended on load amplitude.
\end{abstract}

Keyword: Microhardness; Residual stress; Residual stress relaxation; Shot peening 